\title{
Retirement intentions in the presence of technological change: theory and evidence from France
}

\author{
Pierre-Jean Messe ${ }^{1}$, Eva Moreno-Galbis ${ }^{2,3 *}$ and Francois-Charles Wolff ${ }^{4}$
}

\author{
${ }^{*}$ Correspondence: \\ eva.morenogalbis@univ-angers.fr \\ 2 University of Angers (GRANEM) \\ and CREST and GAINS-TEPP IRES, \\ Erance \\ 3IRES, Belgium \\ Full list of author information is \\ available at the end of the article
}

\begin{abstract}
This paper investigates the role of productivity as a determinant of the worker's retirement intentions. Using an overlapping generation framework, we analyze the retirement decision of a cohort of workers being ability heterogeneous. The labor market is endogenously segmented between workers having the required ability level to occupy jobs where the productivity is indexed to the technological state via on-the-job training (complex jobs) and the rest of workers, who are employed in positions where productivity is relatively deteriorated in case of technological change due to the absence of on-the-job training (simple jobs). In case of technological change, workers in complex jobs delay their retirement date, whereas workers in simple positions will not modify their retirement decision unless taxes change. Using data from France, we find that after a technological change, older workers who benefit from a skill upgrading training program have a higher intended retirement age.
\end{abstract}

JEL: $J 14 ; J 22 ; J 24 ; J 26$

Keywords: OLG; Retirement intentions; Technological change; Training

\section{Introduction}

Many papers have highlighted the negative effect of technical change on older workers' employment rate (Bartel and Sichermann (1993), Aubert et al. (2006), Beckmann (2007), Ronningen (2007) or see Ahituv and Zeira (2011)). They argue that the development of new information and communication technologies accelerates skill obsolescence and reduces therefore both the labor demand and the labor supply of older workers. Little attention has been paid to the impact of technical change on retirement intentions, particularly when it is possible to update the worker's skills.

This paper is an attempt to fill the gap. We investigate how technological change may affect the intended exit age of older workers, both from a theoretical and empirical perspective. We underline the major role of productivity as a determinant of the worker's retirement intentions. The originality of this work consists in showing that technological progress can actually delay the retirement decision of a worker if the worker's skills are updated (via on-the-job training) by the firm. Our paper combines two streams of literature. On the one hand, our work is based on papers analyzing the retirement decision of

(O2014 Messe et al.; licensee Springer. This is an Open Access article distributed under the terms of the Creative Commons 
workers. On the other hand, we employ all the literature interested in on-the-job training issues.

The most recent literature dealing with retirement decision issues focuses on the demand side, and more precisely, on the impact of technological changes on hirings, firings or the share of seniors in the workforce (see Aubert et al. (2006) for France or Borghans and Weel (2002) for the UK). Ljunqvist and Sargent (2008), Cheron et al. (2013) and Saint-Paul (2009) support the view that it is not in the interest of firms to invest in workers having a short working horizon. Langot and Moreno-Galbis (2013) find that for homogeneous productivity workers, only positions occupied by young workers are updated. In contrast, when considering heterogeneous productivity workers, it might be in the interest of the firm to update positions occupied by high productivity workers in spite of being old. Considering productivity issues allows the authors to account for heterogeneous situations within a given age cohort.

In our contribution, productivity differentials among older workers determine their heterogeneous retirement decisions, i.e. we focus on the supply side, rather than on the demand. Productivity differentials arising after the shift in the technological frontier come from heterogeneous training policies: in some jobs workers' skill are updated after a technological change while in some other jobs they are not.

We are not the first to analyze the retirement decision from the supply side. Using US data, Bartel and Sichermann (1993) show that workers in industries with higher average rates of technological change retire later than workers in industries with lower rates of technological progress, since they prefer to smooth the human capital investment they made. On the other hand, an unexpected increase in the rate of technological change induces earlier retirement, since workers do not have the required skills, and due to their short working horizon, they are not motivated to invest in human capital formation. Ahituv and Zeira (2011) suggest another interpretation. They consider that technical progress is made up of an aggregate part, which affects all sectors and a specific part that hits only one sector. They show that the specific part of technical progress has a positive and significant effect on the probability of not working among older workers. This effect may correspond to the standard skill obsolescence effect. In contrast, aggregate technical progress implies an increase in wages, encouraging therefore older workers to delay their retirement age.

Using US data, Friedberg (2003) argues that age is not enough to explain why older workers use computers less. Impending retirement, which reduces the time horizon to recoup an investment in new skills, appears to play a major role. The importance of the working horizon on the retirement choices made by workers is also underlined by Hairault et al. (2010). They estimate that the shorter the distance to retirement (whatever the age of the worker), the lower the probability of being employed. This distance effect becomes active from ten years before retirement.

Concerning the literature interested in the impact of on-the-job training on the relationship between productivity growth and employment decisions, as remarked by Acemoglu and Pischke (1998), all workers' types can benefit from changes in the demand for skills induced by technological progress if they receive training. Bresnahan et al. (2002) conclude that the increased use of information and communication technologies (ICT), changes in organization practices and changes in products and services, taken together are the skill-biased technological progress that calls for a higher skilled labor mix and thus 
for an increased importance of training. ${ }^{1}$ Jobs are on average more and more complex. Computerization is associated with a decline in the demand for routine manual and cognitive tasks and with an increase in the demand for non-routine abstract tasks requiring a wider human capital. ${ }^{2}$

The interplay between technological changes and training is analyzed by Chari and Hopenhayn (1991), who study the lag between the appearance of a technology and its peak usage in an OLG model with ongoing technological change and investment in technology-specific human capital. The interactions between learning by doing, technological choices and the timing of adoption of new technologies are also analyzed in Parente (1994) and Jovanovic and Nyarko (1996). Carre and Drouot (2004) consider a Mortensen and Pissarides (1998) model to analyze how the change in the nature of technological progress modifies on-the-job learning and, through general equilibrium effects, unemployment and wage dispersion. Finally, Moreno-Galbis (2012) shows that, by introducing human capital issues, such as heterogeneous skills, human capital accumulation, on-the-job training and capital-skill complementarity, in a vintage framework in the style of Mortensen and Pissarides (1998), the impact of productivity growth on unemployment rates is magnified.

The contribution of this paper is twofold. First, from a theoretical point of view, we combine an overlapping generations model à la Michel and Pestieau (2000) with a technological diffusion process similar to that proposed in Ahituv and Zeira (2011). However, we introduce the possibility of skill updating (on-the-job training) in some types of jobs and analyze how training modifies retirement decisions in case of technological change. We consider a single generation of individuals that lives two periods. Individuals work during the first period and must choose whether to work or not (early retirement) and the number of years they work during the second period. ${ }^{3}$ Numerical simulations permit to better understand the retirement choices of people employed in heterogeneous types of jobs in case of change in the state of technology.

The second contribution of the paper consists in focusing on the relationship between productivity and senior's employment from the supply side (instead of the demand side, as most of the literature). We exploit a unique cross-sectional French database drawn from the survey Passage à la retraite ("Transitions from work to retirement") conducted in 2006 that contains information about the intended retirement age of respondents aged between 50 and 69 . To investigate the effect of technical change and onthe-job training on retirement intentions, we use the Changements Organisationnels et Informatisation survey (COI, "Organizational Changes and Computerization" survey) conducted in the same year and construct aggregate variables within a local labor market, made up of a specific industry and occupation. Using such recent databases constitutes a great advantage with respect to the existing literature on the subject, since by 2006 there was no incertitude concerning the diffusion process of new technologies among occupations.

The main findings of our paper can be summarized as follows. The theoretical framework and numerical simulations predict that workers whose productivity is improved together with the state of technology (by means of on-the-job training) tend to retire later than workers who do not receive training and bear a relative skill obsolescence in case of technological change. These findings are confirmed by our empirical results. In case 
of technological change, workers employed in jobs displaying a high average training rate plan to retire later than those occupying jobs with a low average training rate. Our findings suggest that on-the-job training may effectively dampen the age bias associated with technical progress.

The remainder of the paper is organized as follows. Section 2 presents the assumptions and the agent's behavior of our theoretical model. Section 3 analyzes the model's predictions by means of numerical simulations. Data and descriptive statistics are displayed in section 4. Section 5 describes the econometric methodology and the results. Section 6 concludes.

\section{The model}

\subsection{Assumptions}

\subsubsection{The life cycle decisions}

We consider an overlapping generations framework à la Michel and Pestieau (2000), where we focus on a single cohort of individuals living for two periods who perfectly anticipate a shift of the technological frontier between their young period and their old period. We assume that each period lasts 30 years, so that the young period will go from the age of 25 to 54 years old and the second period from 55 to 84 years old. During the first period of life individuals work and earn a wage that will be used for consumption and saving. During the second period of life individuals can decide to work for a while or not to work at all. Consumption during this second period is financed by savings made during the first period, by the wage earned during the second period if the individual works and by a retirement pension if the individual does not work.

Expectations are rational, so that the worker chooses from the very beginning of life the optimal amount to save during the young period and the intended retirement date so as to maximize lifetime utility. Because we are mainly interested in the retirement decision we consider the second period of life as the reference period $t$, whereas the first period corresponds to $t-1$. Therefore, our reference cohort of workers entered the labor market in $t-1$ and became old in $t$.

\subsubsection{The production process}

Only one good is produced in the economy. Production only depends on labor, since capital is supposed to be supplied with an infinite elasticity (the interest rate is exogenous). Markets are assumed to be perfectly competitive.

We suppose a continuum of ability levels for workers $a_{t}^{i}$. As in Cheron et al. (2011), the economy includes two types of jobs: simple jobs, where workers do not receive training and so productivity is not modified when the technological frontier shifts; and complex jobs, where, following the shift in the technological frontier, workers receive on-the-job training allowing to index their productivity to the state of technology. We assume that finding a suitable complex job is more costly (it takes a longer time), so workers decide to search for a complex position if and only if their expected gains of occupying a complex job overcome the search cost they bear.

During the first period of life (young period) productivity in simple and complex jobs is determined exclusively by the worker's acquired ability. It is assumed that the education 
system is indexed to the technological frontier so that new entrants into the labor market are endowed with the newest skills allowing them to be fully productive in the labor market. We consider that between the first and the second period of life there is a shift in the technological frontier. Productivity of young people becoming old in complex jobs is improved since we assume they receive the necessary training, whereas productivity of individuals employed in simple jobs remains unaffected since these workers do not receive training.

The distribution of abilities of young workers entering the labor market at date $t-1$ is defined by the interval $a_{t-1}^{i} \epsilon\left[\underline{a}_{t-1}, \bar{a}_{t-1}\right]$. Even if not represented here, these abilities are assumed to be indexed to the state of technology, denoted by $b_{j}$ for $j=t-1, t{ }^{4}$ Between $t-1$ and $t$, the technological frontier shifts. The new state of technology is given by $b_{t}=\left(b_{t-1}+\pi\right)$, where $\pi$ stands for the shift in the technological frontier (gap between the state of technology in the first period and the second period). Productivity of workers occupied in jobs receiving training (complex jobs) improves by the same amount as the technological shift, whereas productivity of workers not receiving training (simple jobs) remains unaffected. ${ }^{5}$ The term $b_{t}$ can therefore be also interpreted as the training effect and it exactly corresponds to the state of technology. At date $t-1$, the productivity of a complex or a simple job equals the ability of the worker. Following the shift in the technological frontier between $t-1$ and $t$, the productivity in jobs receiving training progresses to $y_{t}^{k}=a_{t-1}^{i} b_{t}$ and that of jobs not receiving training remains equal to $y_{t}^{k}=a_{t-1}^{i}$. Retirement decisions of both types of workers will thus differ.

\subsection{The agent behavior}

Pension arrangements provided by the state in most European countries are unfunded, with benefits paid directly from current workers' contributions and taxes. Because our paper analyzes the impact of technological changes on the intended retirement date using French data, our theoretical framework focuses on the retirement decision in the presence of a pay-as-you-go system.

A young individual supplies one unit of labor that provides him a wage $w_{t-1}^{k}$ where $k=C, S$ stands for complex and simple jobs. After paying taxes, the wage will be used both for consumption $\left(c_{t-1}^{k}\right)$ and saving $\left(s_{t-1}^{k}\right)$. During the second period of life, the individual consumes $d_{t}^{k}$, which depends on savings made during the young period, on the retirement pension and on the net wage earned if he keeps working during the old age. Let's denote by $\tau_{j}$ for $j=t, t-1$ the social security tax rate paid over the wages by individuals, $\rho_{t}$ the replacement rate, $R=1+r$ the exogenous interest rate (rate of return to investment) and $z_{t}^{k}$ the amount of time worked by the individual during the second period of life (whose duration is normalized to 1). Consumption in the first and second life periods of individuals belonging to the cohort entering the labor market in $t-1$ are given by:

$$
c_{t-1}^{k}=\left(1-\tau_{t-1}\right) w_{t-1}^{k}-s_{t-1}^{k} \quad \text { and } \quad d_{t}^{k}=R s_{t-1}^{k}+\left(1-\tau_{t}\right) w_{t}^{k} z_{t}^{k}+\rho w_{t}^{k}\left(1-z_{t}^{k}\right)
$$

for $k=C, S$ (complex and simple jobs). 
The individual chooses his savings and proportion of time he will work during his second period of life so as to maximize his lifetime utility:

$$
\begin{aligned}
\operatorname{Max}_{\left\{s_{t-1}^{k}, z_{t}^{k}\right\}} u_{t-1}\left(c_{t-1}^{k}, d_{t}^{k}, 1-z_{t}^{k}\right)= & \log c_{t-1}^{k}+\beta\left(\log d_{t}^{k}+\gamma \log \left(1-z_{t}^{k}\right)\right) \\
\operatorname{Max}_{\left\{s_{t-1}^{k}, z_{t}^{k}\right\}} u_{t-1}\left(c_{t-1}^{k}, d_{t}^{k}, 1-z_{t}^{k}\right)= & \log \left(\left(1-\tau_{t-1}\right) w_{t-1}^{k}-s_{t-1}^{k}\right) \\
+\beta & {\left[\operatorname { l o g } \left(R s_{t-1}^{k}+\left(1-\tau_{t}\right) w_{t}^{k} z_{t}^{k}\right.\right.} \\
& \left.\left.+\rho w_{t}^{k}\left(1-z_{t}^{k}\right)\right)+\gamma \log \left(1-z_{t}^{k}\right)\right]
\end{aligned}
$$

where $\beta$ is the rate of time preference and $\gamma$ corresponds to preference for leisure. ${ }^{6}$

If the individual stops any working activity at the beginning of the second period of life, his retirement pension will equal $\rho w_{t}^{k}$ for $k=C, S$.

The government budget constraint in period $t$ is given by:

$$
\rho\left(1-z_{t}^{S}\right) W_{t}^{o S}+\rho\left(1-z_{t}^{C}\right) W_{t}^{o C}=\tau_{t}\left(W_{t}^{Y}+W_{t}^{O}\right)
$$

where $\rho$ is assumed to be exogenously determined by the government, $W_{t}^{Y}$ stands for the wage bill of young workers, $W_{t}^{O}$ for the wage bill of old employed workers, $W_{t}^{o S}$ for the wage bill associated with old workers employed in simple jobs and $W_{t}^{o C}$ for the wage bill of old workers employed in complex jobs.

Because the objective of this paper is to analyze the retirement decision of a cohort of workers, we focus on the budget constraint of the government at date $t$, when retirement pensions must be paid. The left hand side corresponds to the amount of retirement pensions paid by the government. In a pay-as-you-go system, pensions paid in period $t$ must be financed from taxes paid by workers employed in period $t$. Therefore, the right hand side stands for taxation revenues coming from young employed workers at period $t$ and from old workers who keep working during their second period of life.

\subsection{The equilibrium}

The model's equilibrium can be summarized by three sets of equations:

- Equality between wages and marginal productivity:

$$
\begin{aligned}
w_{t-1}^{i k} & =a_{t-1}^{i} & & \text { for } k=C, S \\
w_{t}^{i C} & =a_{t-1}^{i} \cdot b_{t} & & \text { where } b_{t}>1 \\
w_{t}^{i S} & =a_{t-1}^{i} & &
\end{aligned}
$$

- We assume that in order to have access to complex jobs, the individual needs to make an additional investment in terms of job search since it takes more time and resources to find a complex position suiting his own ability. In order to decide whether to make or not this investment on job search, the worker compares the expected gains and costs of occupying a complex position:

- Occupying a complex position allows the worker to benefit from a higher gross wage following the shift in the technological frontier between the first and the second period of life thanks to training: $w_{t}^{i C}-w_{t}^{i S}=a_{t-1}^{i} \cdot b_{t}-a_{t-1}^{i}=a_{t-1}^{i}\left(b_{t}-1\right)$.

- The search cost, which is indexed to the state of technology, equals $\varphi b_{t}$. 
The threshold ability level below which it is not in the interest of the young individual to pay for the search cost is determined by equalizing the expected gains and costs of occupying a complex position:

$$
a_{t-1}^{i}\left(b_{t}-1\right)=\varphi b_{t} \quad \Rightarrow \quad a_{t-1}^{i *}=\frac{\varphi b_{t}}{\left(b_{t}-1\right)}
$$

All individuals having an ability level above $a_{t-1}^{i *}$ decide to spend more time on searching for a complex position. Complex positions are then occupied by workers having a higher ability level since they have higher expected gains. The search costs represent a kind of filter allowing only the highest ability workers to have access to complex jobs. A higher search cost reduces the number of abilities for which it is interesting to search for a complex position. Conversely, the higher the size of the training effect, $b_{t}$, the larger the number of abilities that searches for a complex position.

- The FOCs associated with the optimizing problem (3) are given by:

$$
\begin{aligned}
\frac{\partial u_{t-1}}{\partial s_{t-1}^{k}} & =0 \Rightarrow s_{t-1}^{k}=\frac{\beta\left(1-\tau_{t-1}\right) w_{t-1}^{k}-d_{t}^{k} / R_{t}}{\beta} \\
\frac{\partial u_{t-1}}{\partial z_{t}^{k}} & =0 \Rightarrow z_{t}^{k}=\frac{\left(1-\tau_{t}-\rho(1+\gamma)\right)-R s_{t-1}^{k} \gamma / w_{t}^{k}}{(1+\gamma)\left(1-\tau_{t}-\rho\right)}
\end{aligned}
$$

for $k=C, S$.

If the individual does not work at all during the second period, i.e. $z_{t}^{k}=0$, his savings and future consumption will equal:

$$
\begin{aligned}
s_{t-1}^{i k} & =\frac{\beta}{1+\beta}\left(1-\tau_{t-1}\right) w_{t-1}^{i k}-\frac{\rho_{t} w_{t}^{i k}}{R(1+\beta)} \\
d_{t}^{i k} & =\frac{\beta}{1+\beta}\left(R\left(1-\tau_{t}\right) w_{t-1}^{i k}+\rho_{t} w_{t}^{i k}\right)
\end{aligned}
$$

where $w_{t}^{i S}=a_{t-1}^{i}$ and $w_{t}^{i C}=a_{t-1}^{i} b_{t}$ (see Appendix).

If the individual decides to work during the second period of life, i.e. $z_{t}^{k}>0$, his optimal choice depends on the type of job we consider:

$$
z_{t}^{i k}=\frac{\left(1-\tau_{t}\right)(1+\beta)-\rho(1+\beta(1+\gamma))-\gamma R \beta\left(1-\tau_{t-1}\right) w_{t-1}^{i k} / w_{t}^{i k}}{\left(1-\tau_{t}-\rho\right)(1+\beta+\gamma \beta)}
$$

where $w_{t}^{i S}=a_{t-1}^{i}$ and $w_{t}^{i C}=a_{t-1}^{i} b_{t}$ (see Appendix).

The analysis of equation (13) allows us to distinguish between three different effects. The first effect corresponds to the term $\left(1-\tau_{t}\right)(1+\beta)$. The higher the tax individuals pay in the second period the shorter the time they decide to work since their net wage will be lower. This effect can though be counterbalanced by the time preference for the future. The second term $-\rho(1+\beta(1+\gamma))$ tells us that the higher the replacement ratio (i.e. the higher the retirement pension) and the higher the preference for leisure, the less the individual is willing to work in the second period. Finally, the term $-\gamma R \beta\left(1-\tau_{t-1}\right) w_{t-1}^{k} / w_{t}^{k}$ captures the trade-off between a wealth effect coming from past savings and a substitution effect coming from the current wage an old individual may earn if he keeps working. The higher the wage earned during the first period with respect to the wage earned during the second period the 
lower $z_{t}^{k}$. While $R \beta\left(1-\tau_{t-1}\right) w_{t-1}^{k}$ stands for the wealth effect, $1 / w_{t}^{k}$ represents the current wage effect (substitution effect). In simple jobs, the last effect is neutralized by the wealth effect and we find $R \beta\left(1-\tau_{t-1}\right)$. In contrast, in complex jobs, the wage effect is dominant. More precisely, since $b_{t}>1$, the negative term in equation (13), that is $R \beta\left(1-\tau_{t-1}\right) 1 / b_{t}$, is smaller than in a simple position, leading to a higher $z_{t}^{C}$. Individuals in complex positions work for a longer period of time.

Replacing in equation (9) yields:

$$
s_{t-1}^{i k}=\frac{1}{R(1+\beta+\gamma \beta)}\left[\beta R\left(1-\tau_{t-1}\right)(1+\gamma) w_{t-1}^{i k}-w_{t}^{i k}\left(1-\tau_{t}\right)\right]
$$

where $w_{t}^{i S}=a_{t-1}^{i}$ and $w_{t}^{i C}=a_{t-1}^{i} b_{t}$ (see Appendix).

In complex positions, $b_{t}>1$, individuals save less since they anticipate a higher future wage. Similarly, because in complex positions individuals work for a longer time and earn a higher wage, future consumption is higher for these individuals (see Appendix).

\subsubsection{The budget constraint}

As observed in equation (13), the fraction of time worked during the second period of life, does not directly depend on the ability distribution. However, it depends on the tax system, $\tau_{t}$ and $\tau_{t-1}$, the training effect, $b_{t}$, and the generosity of the retirement system, $\rho$.

For the sake of simplicity, we normalize abilities of the considered cohort so as they follow an uniform distribution defined between [0,1]. Education follows the technological frontier, so new entrants are endowed with the required skills to fully exploit the most modern technology. Even if our analysis focuses on a single cohort that enters the labor market in $t-1$, when computing the government budget constraint, we must take into account that part of the government resources employed to pay retirement pensions in $t$ come from workers entering the labor market in $t$ and having thus an ability distribution defined by $\left[b_{t} \underline{a}_{t-1}, b_{t} \bar{a}_{t-1}\right]$. The budget constraint at a given date $t$ can then be written as:

$$
\rho\left[1-z_{t}^{S}\left(\tau_{t}, \tau_{t-1}\right)\right] W_{t}^{o S}+\rho\left[1-z_{t}^{C}\left(\tau_{t}, \tau_{t-1}\right)\right] W_{t}^{o C}=\tau_{t}\left[W_{t}^{Y}+W_{t}^{O}\right]
$$

Replacing $W_{t}^{o S}, W_{t}^{o C}, W_{t}^{Y}$ and $W_{t}^{O}$ by their expressions (provided in Appendix) yields:

$$
\begin{aligned}
& \rho\left[\left(1-z_{t}^{S}\left(\tau_{t}, \tau_{t-1}\right)\right) \frac{\left(a_{t-1}^{i *}\right)^{2}}{2}+\left(1-z_{t}^{C}\left(\tau_{t}, \tau_{t-1}\right)\right) \frac{b_{t}}{2}\left(1-\left(a_{t-1}^{i *}\right)^{2}\right)\right]= \\
& \tau_{t}\left[\frac{b_{t}}{2}+z_{t}^{S}\left(\tau_{t}, \tau_{t-1}\right) \frac{\left(a_{t-1}^{i *}\right)^{2}}{2}+z_{t}^{C}\left(\tau_{t}, \tau_{t-1}\right)\left(1-\left(a_{t-1}^{i *}\right)^{2}\right) \frac{b_{t}}{2}\right]
\end{aligned}
$$

The government budget constraint endogenously determines the tax rate that must be paid by the young and the old cohort of workers co-existing at date $t$. The tax rate levied by the government to ensure the budget constraint equilibrium depends on $b_{t}$ and $z_{t}^{k}$, which are themselves affected by the tax rate. Due to the great number of non-linearities (both $z^{S}\left(\tau_{t}, \tau_{t-1}\right)$ and $z^{C}\left(\tau_{t}, \tau_{t-1}\right)$ are functions of the tax rate), we must solve the problem numerically. 


\subsubsection{The retirement decision}

What is the threshold value of preference for leisure from which individuals decide not to work during their second period of life? Setting to zero equation (13) and knowing that $w_{t}^{i S}=a_{t-1}^{i}$ and $w_{t}^{i C}=a_{t-1}^{i} b_{t}$ yields (see Appendix):

$$
\begin{aligned}
\bar{\gamma}^{C} & =\frac{(1+\beta)\left(1-\tau_{t}-\rho\right)}{\beta R\left(1-\tau_{t-1}\right) \frac{1}{b_{t}}-\beta \rho} \\
\bar{\gamma}^{S} & =\frac{(1+\beta)\left(1-\tau_{t}-\rho\right)}{\beta R\left(1-\tau_{t-1}\right)-\beta \rho}
\end{aligned}
$$

The threshold value $\bar{\gamma}^{k}$ decreases with the tax rate of the second period while it increases with the tax rate paid during the young period. That is, to induce individuals to delay retirement, the government should tax them when they are young and reduce taxes during their old age. Preference for leisure thus depends on the taxation system.

The trade-off between the wealth effect and the wage effect appears also in the denominator of equations (17) and (18). A dominant wage effect reduces the value of the denominator increasing the critical value of $\gamma$ above which individuals decide not to work during their senior period of life. Again, we observe that while the wealth effect neutralizes the substitution effect in simple jobs, the opposite holds true for complex positions where there is a dominant wage effect. The threshold value $\bar{\gamma}^{k}$ above which individuals decide not to work during their senior period of life is higher for individuals in complex jobs. Because access to these positions is linked to the acquired ability level of individuals, we can claim that higher ability individuals are more likely to work when becoming seniors.

\section{Numerical simulations}

The quantitative implications of the model concerning the effects of a shift of the technological frontier on the retirement decision are presented as a result of computational exercises. The objective of the numerical simulations is to analyze how a shift in the technological frontier affects the retirement decision of workers depending on whether they have benefitted or not from a training process allowing to update their skills. We consider a particular cohort of workers whose ability distribution is normalized to $[0,1]$ and it is assumed to be indexed to the current state of technology. We will analyze their retirement decision in several scenarios:

- The technological frontier shifts by $b_{t}-b_{t-1}=0.2$.

- The technological frontier shifts by $b_{t}-b_{t-1}=0.2$ and the replacement ratio increases by $\rho_{t}-\rho_{t-1}=0.02$.

- The technological frontier shifts by $b_{t}-b_{t-1}=0.2$ and the replacement ratio decreases by $\rho_{t}-\rho_{t-1}=-0.02$.

- The technological frontier shifts by $b_{t}-b_{t-1}=0.2$ and the search costs increases by $\phi_{t}-\phi_{t-1}=0.03$.

- The technological frontier shifts by $b_{t}-b_{t-1}=0.2$ and the search costs decreases by $\phi_{t}-\phi_{t-1}=-0.03$. 
We study the retirement decision of this cohort of workers for a given shift in the technological frontier and do not consider intergenerational relations. More precisely, we will not analyze how the working decisions made by our cohort affect working decisions made by the co-existing cohort of young workers via taxes. ${ }^{7}$ Our cohort of interest is assumed to enter the labor market at date $t-1$. Under the hypothesis that the economy is initially at the steady state and that the cohort of workers perfectly anticipates the shift in the technological frontier between $t-1$ and $t$, we can easily compute the tax rate paid by the cohort when workers were young as well as the working decision and the tax rate paid by this same cohort of workers when they become old and the technological frontier shifts.

The baseline parameters used in computations are shown in Table 1. We adopt the standard parameter values employed by the literature. More precisely, we consider an annual interest rate equal to $4 \%$ implying that $R=3.24$, since each period lasts 30 years. The rate of time preference between the young and the old period $(\beta)$ equals 0.33 (as in Belan et al. (2010)), preference for leisure $(\gamma)$ is set to 0.5 , search costs of a complex job equal $33 \%$ of the maximum productivity level attainable by the initial cohort of young workers $\left(\phi=0.33 \cdot \bar{a}_{t-1}\right)$ and the replacement ratio $(\rho)$ associated with the pay-as-you go system equals 0.45 .

Our benchmark situation corresponds well to the French economy. Employees in simple jobs retire at the age of 55 and those in complex jobs at the age of 62.62 years old. Around $66 \%$ of the population is occupied in positions where workers receive training in case of technological change (complex jobs). The tax level equals $26.80 \%$.

From this benchmark situation, a shift in the technological frontier by 0.2 points delays retirement of people in complex jobs by five years, whereas retirement in simple positions is delayed by one year and two months (see Table 2). Note that the shift of the technological frontier improves productivity in complex positions, and thus the wage earned by these workers. This wage effect overcomes the wealth effect (savings accumulated during the first life period) and as a result people in complex positions delay retirement. In contrast, productivity in simple positions is relatively deteriorated (since these jobs do not benefit from an increase in productivity). This should tend to relatively advance the retirement decision. However, the reduction in taxes promotes a delay in the retirement date. The reduction in taxes is explained by two factors: on the one hand, wages earned in complex jobs are higher, which allows to increase the receipts, and on the other hand, people in complex positions, who benefit from higher pensions, retire later. Both effects together manage to overcome the increase of the average pension of people going on retirement, so taxes fall.

In the third row of Table 2 we analyze the same shift in the technological frontier but we leave taxes constant at the first period level (26.80\%). In this case, the technological improvement will tend to delay the retirement date for workers employed in complex

Table 1 Baseline parameter values

\begin{tabular}{lc}
\hline Discount factor & $R=3.24$ \\
Rate of time preference & $\beta=0.33$ \\
Preference for leisure & $\gamma=0.5$ \\
Replacement ratio & $\rho=0.45$ \\
Search cost & $\phi=0.33 \cdot \bar{a}_{t-1}$ \\
\hline
\end{tabular}


Table 2 The impact of technological change on the main macroeconomic variables

\begin{tabular}{lcccc}
\hline Benchmark & Retirement age complex & Retirement age simple & $\boldsymbol{\tau}$ & $\boldsymbol{a}^{*}$ \\
\hline$\Delta b=0.2$ & $\mathbf{6 2 . 6 2}$ & $\mathbf{5 5 . 0 0}$ & $\mathbf{0 . 2 6 8 0}$ & $\mathbf{0 . 6 6}$ \\
$\Delta b=0.2 \tau=0.2680$ & 67.88 & 56.20 & 0.1834 & 0.60 \\
$\Delta b=0.2$ and $\Delta \rho=0.02$ & 63.74 & 55.00 & 0.2680 & 0.60 \\
$\Delta b=0.2$ and $\Delta \rho=-0.02$ & 65.24 & 55.00 & 0.2217 & 0.60 \\
$\Delta b=0.2$ and $\Delta \phi=0.03$ & 69.87 & 59.73 & 0.1475 & 0.60 \\
$\Delta b=0.2$ and $\Delta \phi=-0.03$ & 67.80 & 56.06 & 0.1855 & 0.66 \\
\hline
\end{tabular}

positions (whose productivity is improved) while the retirement date of people employed in simple positions remains constant since for them nothing changes with respect to the benchmark simulation (they pay the same taxes and have the same productivity as before the technological shift). In relative terms, people employed in simple jobs retire now earlier than before the technological improvement. ${ }^{8}$ For workers in complex tasks, the retirement age is effectively delayed but by a lower amount than in the case where taxes are allowed to change (in that case, they also benefitted from the reduction in taxes).

A second sensitivity analysis consists in accompanying the shift in the technological frontier with a variation in the generosity of the retirement system. Since we are simply testing the sensitivity of the model to a change in some parameter values, we discretionarily assume $\Delta \rho=0.02$. The fourth row in Table 2 considers an improvement in the generosity of the system whereas the fifth row assumes a deterioration in the generosity of the system. For the former case, we find that employees in simple jobs will go on early retirement while those in complex jobs will retire now at the age of 65.24 instead of 67.88 (taxes attaint now $22.17 \%$, instead of $18.34 \%$ ). For a given shift in the technological frontier, the retirement age of workers will be lower the more generous the retirement pension system. The fifth row in Table 2 confirms these results. When the same technological shift is combined with a less generous pension system $(\Delta \rho=-0.02)$, retirement age is delayed for both people in complex jobs and people in simple jobs (to 69.87 and 59.73 years old, respectively). Taxes are reduced to $14.75 \%$. Leisure appears clearly as a normal good whose demand is increased with income.

The last sensitivity analysis considers the effect of a shift in the technological frontier for various levels of the search cost. As shown by rows 6 and 7 of Table 2, the modification in the search cost essentially influences the share of workers employed in complex jobs (it increases when the search cost falls and it is reduced when the search cost increases). Retirement decisions remain very close to the ones in the second row, when we were only considering a shift on the technological frontier. As a result, taxes are also barely modified.

In sum, a shift in the technological frontier yields workers receiving on-the-job training to delay retirement, since the wage effect manages to overcome the wealth effect. This delayed retirement age together with the increased wage promotes a reduction in the tax rate. This reduced tax induces workers not receiving training (i.e. workers in simple jobs) to delay their retirement age too. In a context of a constant tax rate, the retirement age of workers in simple jobs remains unaffected. Finally, the positive impact of technological progress on the retirement age is lower the higher the generosity of the retirement system.

We now turn to micro data to investigate empirically the impact of a technological change on the retirement intentions of workers depending on whether their productivity 
is indexed to the state of technology, that is, depending on whether workers are trained or not after a technological change.

\section{Data and descriptive statistics}

The purpose of our empirical analysis is to assess whether productivity influences worker's intended retirement age. Our intuition is close to Bartel and Sichermann (1993) and Friedberg (2003). In case of a technological change, workers are expected to advance their retirement date but only if they suffer a drop in their productivity. If their skills are updated, we expect that technical change encourages workers to delay their exit age.

A difficulty here is that we do not have a direct measure of the worker's productivity in our datasets and especially we do not know how it may vary after a shift in the technological frontier. To overcome this problem, we proceed in the following way. We argue that workers benefiting from on-the-job training after a technological change will see their productivity indexed to the state of technology, whereas workers not concerned with a training program will suffer skill obsolescence. This corresponds well to our theoretical framework according to which workers in complex positions see their productivity improved together with the state of technology, whereas workers in simple jobs suffer a skill obsolescence process. We combine individual data including information on the intended exit age of workers and aggregate data on both ICT adoption and participation to firm-sponsored training session.

\subsection{The "Transitions from work to retirement" survey}

We exploit a unique cross-sectional survey entitled "Transitions from work to retirement" (TWR hereafter) conducted by the National Institute of Statistics and Economic Studies in France in 2006. This data set corresponds to an ad hoc module of the annual French Labour Force survey conducted during that specific year and concerns all people aged from 50 to 69 years old (so born between 1937 and 1956). Detailed demographic and economic characteristics of respondents are obtained by matching the TWR survey with the 2006 Labour Force survey.

Our main variable of interest is the intended retirement age. While some authors have focused on transitions from work to retirement (see Behaghel et al. (2010)) in France, we choose to focus on retirement intentions of older workers. Several studies have shown the relevance of such self-reported indicators. Using the first two waves of the Health and Retirement Study, Dwyer and $\mathrm{Hu}$ (2000) have shown that among workers who planned at wave 1 to retire by wave 2, more than one half was effectively fully or partially retired the next wave. Using the same dataset, Benitez-Silva and Dwyer (2005) conclude that retirement intentions are consistent with rational behavior.

To provide some evidence on the reliability of retirement intentions for the French case, we have estimated robust correlation between the proportion of workers aged 50-55 years old in 2006 and expecting to leave the labor market at 60 or after, computed at the industry-occupation level from the 2006 TWR survey, and the proportion of workers aged 55-59 years old still employed five years later, also computed at the industry-occupation level using the 2011 French Labour Force survey. We find a statistically significant correlation of 0.413 which makes us confident about the use of retirement intentions to predict effectively retirement behavior. 
Since we are interested in retirement intentions, we focus on respondents who are still working at the time of the survey $(\mathrm{N}=5,490) .{ }^{9}$ Admittedly, this restriction is likely to lead to a selection bias, since among older respondents, those willing to retire early have presumably already left the labor market. In Figure 1, we represent the share of employed workers in the whole population of respondents by age. Among individuals aged 57 years old or more, those still working account for less than $50 \%$ of the total number of respondents. After 60, this share is even less than $20 \%$. A simple strategy to avoid this selection bias consists in keeping the youngest workers only. Thus, we restrict our sample to working male respondents aged 55 years old or less and exclude self-employed workers. Also, we decide to focus on the retirement intentions of men only as the retirement behavior of women may be more affected by family considerations. This leaves us with a sample of 1,430 male respondents.

Our dependent variable is the age at which workers intend to leave the labor market. Respondents have to choose one of the three following categories in the TWR questionnaire: i) before reaching 60 years old, ii) between 60 and 64 years old, or iii) after 64 years old. ${ }^{10}$ The TRW dataset includes a large set of control variables that may explain retirement intentions. For each respondent, we have information on age, gender, marital status, health status, educational level, working in private or public sector, job tenure, full-time or part-time job, and monthly wage.

As noted by Hairault et al. (2010), retirement decisions in France are strongly correlated to financial incentives of the Social Security system and especially to the distance to the full pension age. In the 2006 TWR survey, individuals report the number of years they have contributed to the pension system so far. As in 2006, the required number of contribution years to be entitled to a pension at the highest replacement rate is 40 years, the distance to the full pension age is obtained by subtracting the number of years individuals have already contributed from 40. Given the French legislation in 2006, we also

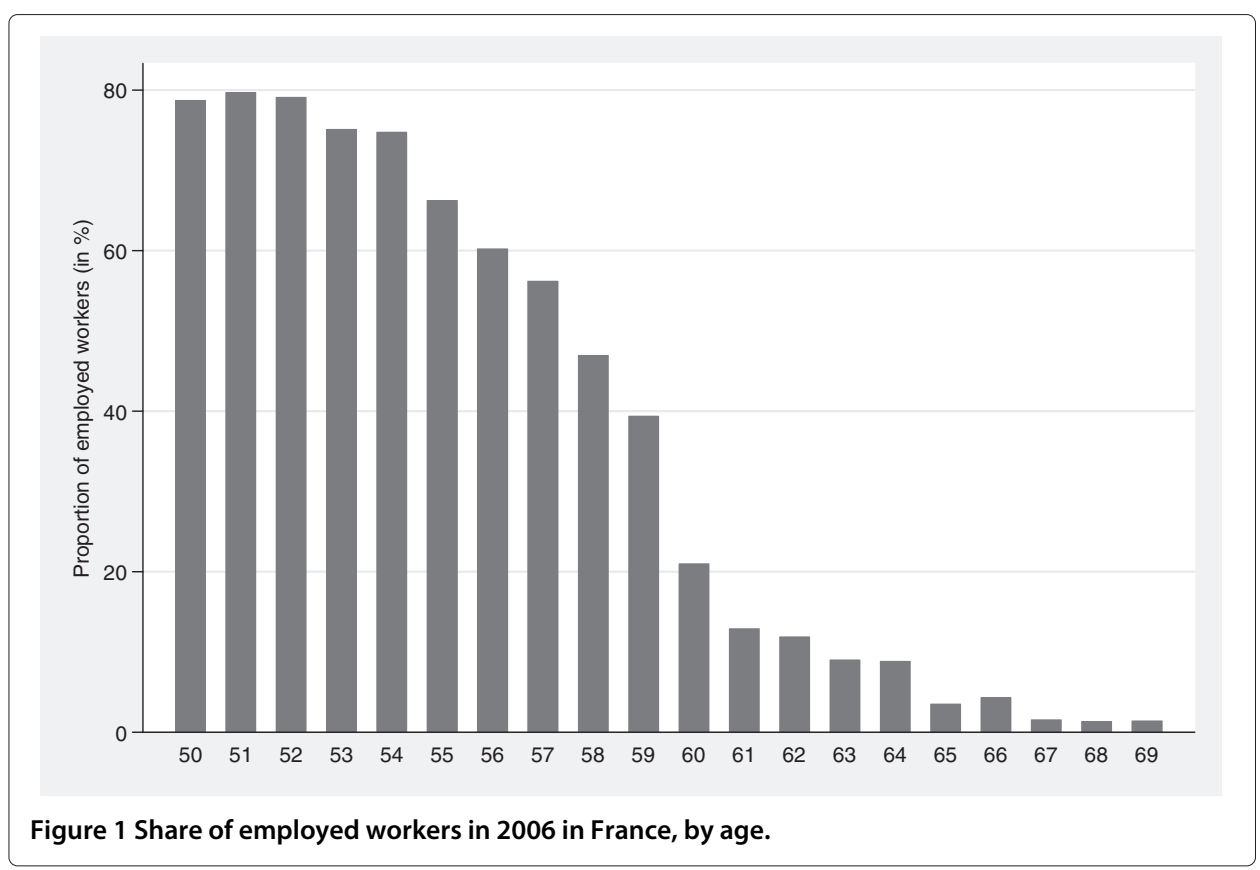


account for the fact that older workers reaching 65 can be entitled to the highest replacement rate, even when they have not contributed during 40 years. Formally, the distance $D_{i}$ to the full pension age for an individual of age $a_{i}$ having already contributed $C_{i}$ years is $D_{i}=\min \left\{40-C_{i} ; 65-A_{i}\right\}$.

\subsection{Aggregate data on technological change and productivity}

Next, we need some information on the way workers are affected by technological changes in their work environment and also on the probability that their skills are updated after such a shock. As far as we know, there is no individual survey that gathers information on retirement intentions, technical changes in the work environment and training participation. So, we choose to merge the TWR individual data on retirement intentions with aggregate data on ICT adoption and participation to firm-sponsored training session coming from a matched employer-employee survey on organizational change and computerization (COI) conducted in 2006 by the Ministry of Labour and the Centre d'Etudes de l'Emploi. As a few sectors are missing in this database, (e.g. associative sector or some public administrations), we end up with a sample of 1,159 male respondents after merging TWR data with COI.

The employee-level COI survey allows to measure the incidence of technical change and on-the-job training accounting simultaneously for the industrial and occupational specificity of the respondent's job. This is in line with our theoretical model in which the effect of a technological change on retirement intentions may vary between different types of jobs. An important issue here consists in the choice of the aggregation level. This implies a trade-off between having the finest decomposition and having a sufficient number of individuals in each industry-occupation cell. In what follows, we define industries using the NAF-36 classification and consider four occupations: managers, technicians, clerical workers and blue-collar workers.

Our data was collected in 2006, several years after the ICT boom. So simple indicators of ICT use do not correspond to a technological change. Therefore, we consider the probability for workers of having experienced a technical change in their work environment over the last three years. ${ }^{11}$ We compute this indicator for each industry-occupation cell.

Respondents were also asked whether they have participated over the last three years to a firm-sponsored training session on the use of new softwares or new computer devices. We use this information to define for each industry-occupation cell the proportion of workers having been trained. This type of training relates to some specific skills that may become quickly obsolete after a technological change. We choose to consider the proportion of trained workers rather than the duration of training, given that $75 \%$ of the training sessions on the use of computer tools last for less than one week. While one week duration may seem very short, it is in line with the average duration of training sessions in France in 2006. ${ }^{12}$ In addition, most training sessions in which older workers participated were aimed at adapting the worker to the job he already occupied, which does not require a lot of time.

When working with these aggregate variables, restricting our sample to older workers (above 50) may lead to some selection bias. Indeed, older workers who participate on a training session on new computer tools may intend to retire later because skill updating induces improved work opportunities. At the same time, employers may be tempted to invest in the skills of the employees who intend to postpone their retirement 
age (reverse causality). Potentially, this simultaneity issue may also be problematic for our indicator of technological change. Retirement intentions of older workers may have been internalized by employers, therefore influencing their decision of adopting new technologies.

To address this issue, we follow the approach of Friedberg (2003) by considering workers aged 24-49 rather than workers aged 50 or more when constructing our aggregate indicators. The underlying idea is that a high likelihood of skill updating among workers aged 24-49 implies that the gains for the employer are higher than the training cost in this specific industry-occupation cell. The identifying assumption is to consider that the training incentives among workers aged 24-49 years are not correlated with their retirement considerations. For a sake of robustness, we have also considered several other age groups further from retirement, in particular the 25-40 years interval. ${ }^{13}$ This does not have any effect on our results.

As our variable of technical change is self-reported by the worker, it may be subject to classical measurement errors. To ensure the validity of this indicator as a good proxy for measuring technical change, we exploit the information contained in the COI data at the employer-level. More precisely, employers are asked about the introduction of some modern management tools and ICT equipment in their firm, at the time of the survey (in 2006) and also three years before (in 2003). Regarding ICT, we take 15 items into account and provide a description of these items in Table 3.

We rely on indicators built by Bigi et al. (2013) synthesizing the intensity of ICT use in 2003 and 2006 by Multiple Correspondence Analysis (MCA) and then compute an indicator of intensity of technical change for each firm between these two years. ${ }^{14}$ The advantage of this indicator of technical change is that it reduces the risk of measurement error, given that it is directly reported by employers. However, while this variable is computed at the firm-level, it could be that the new ICT tools have been implemented for some type of jobs but not for others. Consequently, we could miss some information on the probability of technical change at the industry-occupation level. This information,

Table 3 Presence of ICT tools in productive units

\begin{tabular}{lcc}
\hline \% of productive units with ICT tools & $\mathbf{2 0 0 3}$ & $\mathbf{2 0 0 6}$ \\
\hline Website & 61.2 & 73.3 \\
Local Area Network (LAN) & 61.3 & 66.7 \\
Intranet & 47.9 & 57.8 \\
Extranet & 25.0 & 30.2 \\
Electronic data interchange system & 36.2 & 45.8 \\
Using an Enterprise Resource Planning (ERP) & 26.6 & 29.6 \\
Database for research & 26.1 & 28.8 \\
Database on the management of Human Resources & 34.5 & 38.5 \\
Use of software or firmware for research & 47.4 & 49.8 \\
Use of software or firmware for the & & \\
management of Human Resources & 63.4 & 65.3 \\
Tools for data analysis & 39.5 & 47.1 \\
Tools for interfacing databases & 21.1 & 28.6 \\
Tools for automated data archiving or research & 21.4 & 27.4 \\
Collaborative tools (groupware) & 15.1 & 21.0 \\
Tools for process modelling & 8.8 & 12.7 \\
\hline Sources: COI (2006)/INSEE-DARES-CEE, Bigi et al. (2013). & &
\end{tabular}

Sources: COI (2006)/INSEE-DARES-CEE, Bigi et al. (2013). 
extracted from the employer-level survey, will be used to test the validity of this covariate at the industry level.

\subsection{Descriptive statistics}

We build our theoretical model on the main assumption that, in case of technological change, older workers occupying complex jobs receive training even though their working horizon is short. Using the 2000 French Complementary Survey on Training, Langot and Moreno-Galbis (2013) show that $34 \%$ of managers and $21 \%$ of technicians between 56 and 60 years old still receive firm-sponsored training in case of technological change. However, these figures may be subject to some selection bias. Indeed, we have already shown in Figure 1 that after 55, the probability to remain employed falls dramatically.

Using our training variable from the COI employee-level data and restricting our sample to workers aged 50-55, we investigate whether access to training may vary across jobs of different skill levels, holding the working horizon constant. We decompose workers into three groups: the first is close to the full pension age (two years or less), the second is further from retirement (between three and eight years from the full pension age) and the third is too far from retirement (nine years or more). As shown in Figure 2, the training rate is still high for managers, even for those who are at two years or less from the full pension age, and varies across skill levels.

Now we describe retirement intentions of French male workers in 2006 as well as their individual characteristics. Table 4 shows that, while $48.6 \%$ of occupied male respondents aged 50-55 intend to exit the labor force between 60 and 64, 38.7\% plan to leave before 60 and only $12.7 \%$ report an intended exit age of 65 or more. When comparing the distributions of covariates in each column, we see that the distance to retirement is strongly positively correlated with intended exit age. This is consistent with previous empirical findings of Hairault et al. (2010). As the distance to full pension age increases with the exit age from the schooling system, it is not surprising that the higher the educational level,

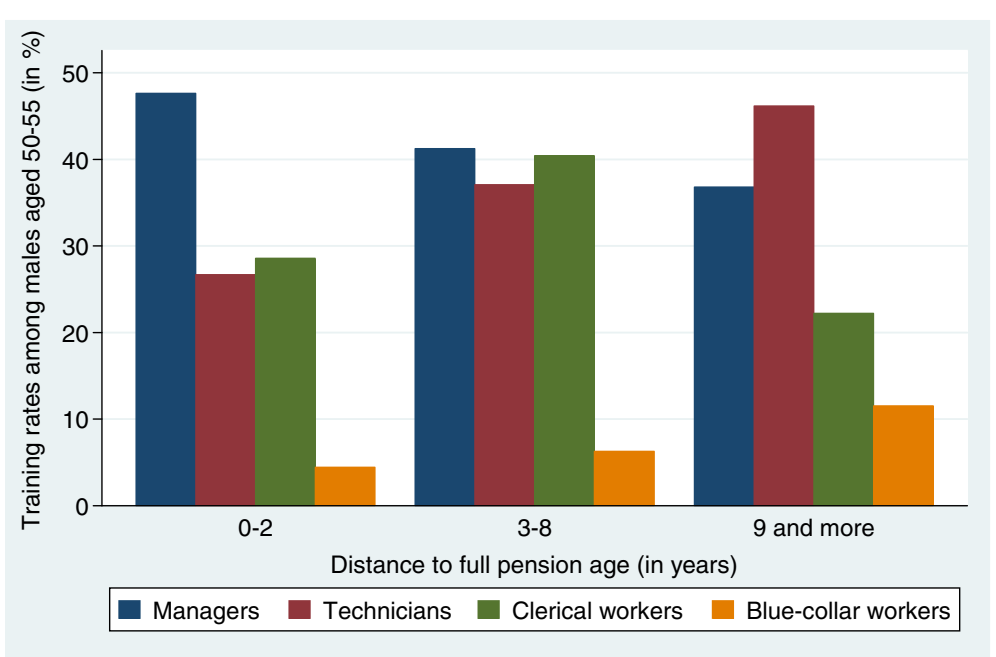

Figure 2 Proportion of trained males at different career horizons across skill levels. Note: The career horizon is defined as the difference between the full pension age and the age of the respondent. The full pension age is determined by the required number of contributive years to be entitled to a pension at the highest replacement rate. 
Table 4 Descriptive statistics

\begin{tabular}{|c|c|c|c|c|}
\hline \multirow[b]{2}{*}{ Variables } & \multicolumn{3}{|c|}{ Intended retirement age } & \multirow[b]{2}{*}{ All } \\
\hline & Less than 60 & $60-64$ & 65 or more & \\
\hline \multicolumn{5}{|l|}{ Individual characteristics } \\
\hline Age & 52.38 & 52.43 & 52.38 & 52.41 \\
\hline Single & 0.127 & 0.160 & 0.204 & 0.153 \\
\hline \multicolumn{5}{|l|}{ Education } \\
\hline Primary & 0.385 & 0.279 & 0.293 & 0.322 \\
\hline Secondary/Nocational & 0.510 & 0.405 & 0.265 & 0.428 \\
\hline High School & 0.056 & 0.123 & 0.156 & 0.101 \\
\hline Undergraduate & 0.031 & 0.099 & 0.075 & 0.070 \\
\hline Graduate/Postgraduate & 0.018 & 0.094 & 0.211 & 0.080 \\
\hline \multicolumn{5}{|l|}{ Occupation } \\
\hline Managers & 0.076 & 0.250 & 0.333 & 0.193 \\
\hline Technicians & 0.245 & 0.250 & 0.197 & 0.242 \\
\hline Clerical workers & 0.105 & 0.099 & 0.116 & 0.104 \\
\hline Blue-collar workers & 0.575 & 0.400 & 0.354 & 0.462 \\
\hline Good/very good health & 0.728 & 0.787 & 0.816 & 0.768 \\
\hline Public sector & 0.140 & 0.197 & 0.143 & 0.168 \\
\hline Part-time job & 0.022 & 0.036 & 0.088 & 0.037 \\
\hline Years to full pension age & 3.737 & 5.535 & 6.680 & 4.984 \\
\hline \multicolumn{5}{|c|}{ Aggregated variables for workers aged 24-49 years } \\
\hline \multicolumn{5}{|c|}{ At the industry-occupation level } \\
\hline Average probability of a technical change & 0.344 & 0.314 & 0.308 & 0.325 \\
\hline Average probability of skill updating & 0.199 & 0.227 & 0.231 & 0.217 \\
\hline Number of observations & 449 & 563 & 147 & 1159 \\
\hline Share of employed workers & $38.74 \%$ & $48.58 \%$ & $12.68 \%$ & $100 \%$ \\
\hline
\end{tabular}

Sources: COI (2006)/INSEE-DARES-CEE, TWR survey.

the higher the intended retirement age. $21.1 \%$ of individuals who intend to exit their job after 65 are graduate or post-graduate, while this proportion is equal to $7.9 \%$ on average.

Our goal is to study the link between retirement intentions and some characteristics of the work environment affecting productivity, such as the frequency of technical change or the chance to receive firm-sponsored training, computed at the industryoccupation level. We find a positive correlation equal to 0.159 between average training rates observed for a job (for workers aged 24-49) and the intended exit age of workers occupying that job. While on average training rates equal $21.7 \%$, jobs occupied by workers reporting the highest intended exit age display average training rates of $23.1 \%$ and those occupied by workers reporting the lowest intended exit age display average training rates of $19.9 \%$.

Furthermore, there is a negative correlation (equal to -0.143) between the probability of a technical change at the industry-occupation level and the intended exit age. As shown in Table 4, jobs occupied by individuals with high intended retirement age are on average less likely to be hit by a technical change than jobs occupied by workers willing to exit early. This is consistent with previous findings of Bartel and Sichermann (1993) and Ahituv and Zeira (2011). However, contrary to the latter, we allow older workers' skills to be updated after the shock. So, we examine whether the effect of a technical change on retirement intentions of workers may depend on the way their productivity is indexed to the state of technology through on-the-job training. 


\section{Econometric results}

\subsection{Technical change and retirement intentions}

We investigate the effect of technical change computed at the industry level on retirement intentions of older workers. Since the information on individual retirement intentions is measured by an ordered variable, we turn to an ordered Probit regression to explain the determinants of retirement intentions.

We first include only a set of individual-specific characteristics described in Table 4 . Then, we add the average probability of technical change in the regression. This variable is introduced in two ways. First, we consider the average probability, computed at the industry-level, that workers report having experienced a change in the techniques used over the last three years. Second, we exploit the continuous indicator of the intensity of change in ICT-use, built from employers' declaration. We decompose this variable into quartiles and consider for each industry the proportion of workers whose employers report a high intensity of technical change. ${ }^{15}$ This allows us comparing our indicator of technical change, reported by employees, with another measure of change derived directly from the employer survey. To account for the correlation of observations at the industry level, we correct standard errors using a clustering procedure following (Moulton (1990)). Our results are reported in Table 5.

First, we discuss briefly the coefficients obtained by regressing the ordered variable of intended exit age on our set of individual characteristics (column 1). Since we introduce some indirect determinants of individual wage, like for instance educational level or occupation, we do not include the wage in the set of covariates to avoid potential multicollinearity issues. ${ }^{16}$ The estimates show the salient role of age to predict retirement intentions, in line with previous results of Taylor and Shore (1995) for the US. Furthermore, the distance to full pension age exerts a strongly positive and significant effect on the intended exit age, which corresponds well to the horizon effect highlighted by Hairault et al. (2010). ${ }^{17}$ We also find a positive correlation between intended exit age and both health status and occupation.

Then, we examine the effect of our industrial indicators of technical change on the intended exit age of respondents (columns 2 and 3). We obtain similar results whether we consider our variable of technical change from the employee data or the indicator directly reported by employers and consequently less subject to measurement error. We find that both variables have a negative and significant effect on the intended retirement age. As these variables relate to a technical change specific to the industry, our findings are consistent with the erosion effect highlighted by Ahituv and Zeira (2011).

\subsection{Technical progress, retirement intentions and skill updating}

Next we estimate the same ordered regressions as before but consider aggregate variables at the industry-occupation levels. So, standard errors are now clusterized at the industryoccupation level. First, we study the effect of the average probability of participating to firm-sponsored training session on the use of new computer devices on retirement intentions. Recall that this probability is computed for workers aged 24-49, so it allows to remove a potential simultaneity bias. Then, we investigate how technical change may interact with training to influence retirement intentions of workers. We report our results in Table 6. 
Table 5 Ordered Probit estimates of the intended retirement age, with technical change at the industry level

\begin{tabular}{lccc}
\hline Variables & $\mathbf{( 1 )}$ & $\mathbf{( 2 )}$ & $\mathbf{( 3 )}$ \\
\hline Single & $0.169^{*}$ & $0.165^{*}$ & $0.178^{* *}$ \\
& $(0.088)$ & $(0.087)$ & $(0.085)$ \\
Age & $0.182^{* * *}$ & $0.181^{* * *}$ & $0.182^{* * *}$ \\
& $(0.030)$ & $(0.030)$ & $(0.030)$
\end{tabular}

\section{Education}

(ref: Primary)

Secondary/Nocational

$\begin{array}{ccc}-0.156^{* *} & -0.136^{* *} & -0.147^{* *} \\ (0.072) & (0.078) & (0.075) \\ -0.007 & 0.018 & -0.008 \\ (0.123) & (0.129) & (0.124) \\ -0.234 & -0.260 & -0.272 \\ (0.222) & (0.208) & (0.213) \\ -0.046 & -0.108 & -0.116 \\ (0.173) & (0.159) & (0.179)\end{array}$

\section{Occupation}

(ref: Blue-collar workers)

Managers

$0.366^{* *}$

$0.373^{* * *}$

$0.359^{* * *}$

Technicians

(0.135)

(0.134)

(0.127)

Clerical workers

0.082

0.140

0.122

Clerical workers

(0.117)

(0.110)

(0.102)

0.073

0.146

0.114

Public sector

$(0.204)$

(0.175)

(0.207)

$-0.189 * *$

$-0.252^{* *}$

$-0.253^{* * *}$

Part-time job

(0.093)

(0.097)

(0.090)

$0.357^{*}$

0.315

$0.385^{*}$

Good/very good health

(0.216)

(0.241)

$(0.216)$

$0.192^{* *}$

$0.186^{* *}$

$0.206^{* *}$

(0.081)

(0.084)

$0.160^{* * *}$

$0.161^{* * *}$

(0.081)

Years to full pension age

(0.015)

(0.015)

$0.163^{* * *}$

\section{Variables of technical change at the industrial level}

Average probability of a technical change

Proportion of workers in firms

with high intensity of change in ICT use

\begin{tabular}{lccc}
\hline Observations & 1159 & 1159 & 1159 \\
\hline Log pseudolikelihood & -984.67 & -979.04 & -979.17 \\
Pseudo $R^{2}$ & 0.133 & 0.138 & 0.138 \\
\hline
\end{tabular}

Note: estimates from ordered Probit model, the dependent variable being equal to 1 when the respondent intends to leave the labor market before 60, 2 when his intended exit age ranges from 60 to 64 , and 3 if he intends to leave the labor market at 65 or after. Standard errors (in parentheses) are clustered at the industry level, significance levels being $1 \%\left({ }^{* * *}\right), 5 \%\left(^{* *}\right)$ and $10 \%(*)$. The average probability of technical change is the probability that workers employed in a specific sector report having experienced a change in the techniques used over the last three years.

The proportion of workers in firms with high intensity of change in ICT (COl employer data) corresponds to the highest quartile of our synthetic indicator on technical change.

Source: COI (2006)/INSEE-DARES-CEE, TWR survey (2006), French Labour Force Survey 2006.

In column 1, we see that training encourages older workers to delay their retirement decisions. This finding is in line with previous work of Picchio and Van-Ours (2013), who suggest additional on-the-job training to maintain older workers in employment 
Table 6 Estimates of intended retirement age, with technical change at the industry-occupation level

\begin{tabular}{lccc}
\hline Variables & $\mathbf{( 1 )}$ & $\mathbf{( 2 )}$ & $\mathbf{( 3 )}$ \\
\hline Aggregated variables for workers aged 24-49 years & & & \\
Average probability of skill updating $\left(T_{1}\right)$ & $1.324^{* *}$ & -0.396 & -0.215 \\
& $(0.680)$ & $(0.964)$ & $(0.955)$ \\
Average probability of a technical change $\left(T_{2}\right)$ & & $-0.803^{* *}$ & $-0.719^{* * *}$ \\
& & $(0.263)$ & $(0.244)$ \\
Interaction term $\left(T_{1} * T_{2}\right)$ & & $4.942^{* * *}$ & $5.053^{* * *}$ \\
& & $(1.905)$ & $(1.74)$ \\
Control variables & YES & YES & YES \\
Occupation fixed effects & YES & YES & YES \\
Industry fixed effects & YES & YES & YES \\
Observations & 1159 & 1159 & 1159 \\
\hline Log pseudolikelihood & -911.79 & -926.44 & \\
Pseudo $R^{2}$ & 0.182 & 0.184 & 0.3524 \\
\hline
\end{tabular}

Note: (1) and (2) are estimates from ordered Probit model, the dependent variable being equal to 1 when the respondent intends to leave the labor market before 60, 2 when his intended exit age ranges from 60 to 64 , and 3 if he intends to leave the labor market at 65 or after. Standard errors (in parentheses) are clustered at the industry-occupation level, significance levels being $1 \%\left({ }^{* *}\right), 5 \%\left({ }^{* *}\right)$ and $10 \%\left({ }^{*}\right)$. (3) are estimates from an OLS regression on the latent outcome associated with retirement intention. The latent variable has been obtained using simulated residuals. The other control variables are those used in the regressions reported in Table 5.

Source: COI (2006)/INSEE-DARES-CEE, TWR survey (2006), French Labour Force Survey 2006.

or with the work of Behaghel et al. (2010) who show that training reduces significantly the exit rates among older workers. However, the role of training on retirement intentions turns out to be strongly driven by the interaction with technical change. Indeed, in column 2, we see that the coefficient associated with the interaction term is strongly significant and positive while the effect of the probability of skill updating becomes non significant.

At first sight, this result seems consistent with our theoretical predictions. In jobs with a high probability of skill updating, technical change may encourage workers to delay their intended exit age. However, as noted by Ai et al. (2004), the effect of an interaction term in a non-linear model is difficult to interpret. The problem is even more complex in our case since the dependent variable is ordered and not binary. To assess the role played by training, we decide to rely on the latent variable measuring the propensity to delay the retirement decision. We implement the following methodology to overcome the unobservability of this latent outcome: let $Y_{i}=k$ be the categorical variable of respondent $i$ measuring retirement intention, with $k=1$ when the intended exit age is lower than $60, k=2$ when it ranges from 60 to 64 , and $k=3$ when it is higher than 64 . Denoting by $Y_{i}^{*}$ the latent outcome such that $Y_{i}^{*}=\beta X_{i}+\epsilon_{i}\left(X_{i}\right.$ is the set of control variables), we know that $Y_{i}=k$ when $\mu_{k}<Y_{i}^{*} \leq \mu_{k+1}$, where $\mu_{0}$ is set to $-\infty$ and $\mu_{3}$ to $+\infty$. The problem we must solve is that of the unobservability of $Y_{i}^{*}$. A simple solution is to rely on the methodology of simulated residuals originally proposed by Gouriéroux et al. (1987).

The first step is to estimate by maximum likelihood the ordered Probit model as done in Table 6, which gives consistent estimates for $\hat{\beta}$ and $\hat{\mu}_{k}$. Then, residuals $\epsilon_{i}$ are drawn from the normal distribution for each respondent until the condition $\hat{\mu}_{k}<\hat{\beta} X_{i}+\epsilon_{i} \leq$ $\hat{\mu}_{k+1}$ is satisfied. The latent outcome $Y_{i}^{*}$ is such that $Y_{i}^{*}=\hat{\beta} X_{i}+\epsilon_{i} \cdot{ }^{18}$ The final step is to estimate $Y_{i}^{*}$ as a function of $X_{i}$ using an OLS regression. The regression 
includes both the average probability of skill updating, the average probability of technical change and an interaction term crossing these two covariates. As shown in column 3 of Table 6, we find very comparable results for the ordered regression on the categorical retirement variable and for the OLS model estimated on the latent propensity to delay retirement. ${ }^{19}$

Using the method of simulated residuals, we can now interpret the interaction term in a straightforward way. We see in column 3 of Table 6 that the negative effect of the average probability of a technical change, computed at the industry-occupation level, on the workers' propensity to delay their retirement decision may become strongly positive if the average training rate is sufficiently high. To provide a graphical illustration, we plot the propensity to delay the retirement decision as a function of the average probability of technical change, setting the probability of skill updating to 0 (simple jobs) in one case and to 1 (complex jobs) in the other case.

The magnitude of the interaction term is determined by examining the difference in slopes between the two lines. We report using horizontal lines in Figure 3 the two threshold values obtained from the ordered Probit model (column 2 of Table 6). The first threshold $\mu_{1}=9.91$, represented by the lower horizontal dash-dotted line, corresponds to the value of the latent outcome below which respondents intend to leave their job before 60 . The second threshold $\mu_{2}=11.73$, represented by the upper horizontal

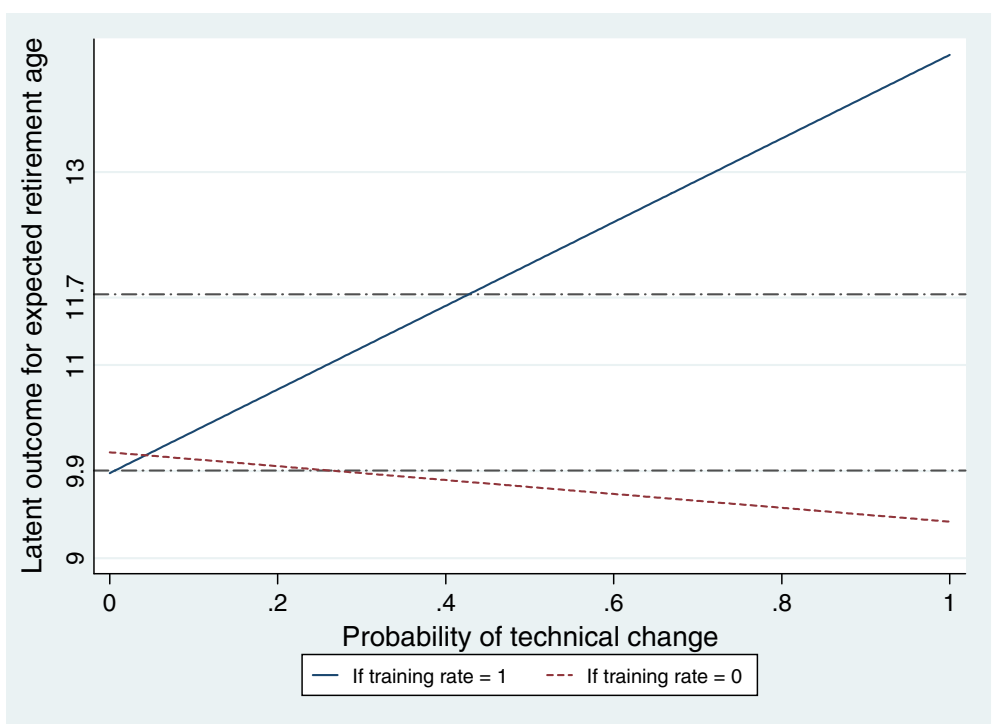

Figure 3 Marginal effect of technical change on the propensity of older workers to delay their retirement decision. Lecture: The latent outcome associated to the ordered intended retirement age (with three categories) is obtained by the methodology of simulated residuals. The lower horizontal dash-dotted line represents the threshold value of the latent outcome below which the respondents intend to leave their job before 60. This value is $\mu_{1}=9.91$. The upper horizontal dash-dotted line represents the threshold value of the latent outcome value of the latent outcome above which respondents intend to leave their job at 65 or after. This value is $\mu_{2}=11.73$. Both thresholds are those from the ordered Probit regressions explaining intended retirement age, whose estimates are used when applying the method of simulated residuals. The dashed decreasing line represents the latent outcome as a function of the average probability of technical change, computed at the industry-occupation level, in the case where the average training rate computed at the industry-occupation level among the workers aged 24-49 years old, is set to 0 . The solid increasing line stands for the latent outcome as a function of the average probability of technical change in the case where the average training rate is set to 1. 
dash-dotted line, stands for the value of the latent outcome above which respondents intend to leave their job at 65 or after.

Figure 3 shows that the dashed line, corresponding to simple jobs, is decreasing with the average probability of technical change. So, in absence of training, technical change discourages older workers to continue their activity. While in simple jobs without technical change, workers may intend to exit the labour force between 60 and 64, a high probability of technical change leads these workers to advance their retirement intentions to less than 60 years old. The solid line in Figure 3, corresponding to complex jobs, is increasing with the average probability of technical change. So, in jobs in which productivity is indexed to the shift in the technological frontier, technical change may encourage older workers to retire later.

For complex jobs, the erosion effect of technical change is not only mitigated by training but is rather reversed. In some stable work environment (low probability of technical change), the intended exit age ranges from 60 to 64. However, in jobs characterized by a high probability of technological change (higher than 0.45 as shown in Figure 3), workers expect to leave their job at 65 or after if they benefit from training to update their skills. This is in line with our previous empirical results, when we found that the effect of training on retirement intentions was strongly driven by the degree of technical change.

\subsection{Robustness check}

The positive and significant interaction term found in Table 6 may reflect the fact that high-ability workers are less affected by technological change than low-ability workers simply because they receive more training. ${ }^{20}$ Even though dealing properly with this selection issue is not really possible with data on hand, we test whether this interaction term remains positive and significant by making a distinction between managers and the rest of the workers, that is, between workers having the highest probability of receiving training and the rest of the workers. Specifically, we run the same estimates as in columns 2 and 3 of Table 6 for each category of workers. Since the average probability of a technical change and the average probability of receiving training are computed at the industryoccupation level, we exploit the variability across industries. We present the obtained results in Table 7.

In the absence of training, we find that the average probability of technological change affects negatively the intended retirement age of all workers, regardless on whether they are managers or not. Then, if workers' skills are not updated, the erosion effect applies for all type of workers, even the high-ability ones. We also obtain a positive and significant coefficient associated with the interaction term for managers. This suggests that training strongly matters when we study the effect of technical change on the retirement intentions of older workers, even for high-ability ones.

These findings put forward that what matters regarding retirement intentions and especially early exit decisions is not the technical change but the way the productivity of the job is indexed to the shift of the technological frontier (through on-the-job training). So, technical progress will not necessarily encourage older workers to early retirement if employers allow their productivity to be indexed to the state of technology through a better access to training. This provides some evidence of the major role on productivity as a determinant of retirement decisions. 
Table 7 Estimates of the intended retirement age by occupation, with technical change at the industry-occupation level

\begin{tabular}{|c|c|c|c|c|}
\hline \multirow[b]{2}{*}{ Variables } & \multicolumn{2}{|c|}{ Managers } & \multicolumn{2}{|c|}{ Other occupations } \\
\hline & (1) & $(2)$ & (3) & (4) \\
\hline \multicolumn{5}{|c|}{ Aggregated variables for workers aged 24-49 years } \\
\hline \multirow[t]{2}{*}{ Average probability of skill updating $\left(T_{1}\right)$} & -0.732 & -0.625 & -0.034 & -0.562 \\
\hline & $(1.125)$ & $(0.920)$ & $(0.758)$ & $(0.639)$ \\
\hline \multirow[t]{2}{*}{ Average probability of a technical change $\left(T_{2}\right)$} & -2.951 & $-3.250^{* *}$ & $-1.048^{* * *}$ & $-1.204^{* * *}$ \\
\hline & $(1.963)$ & $(1.618)$ & $(0.254)$ & $(0.255)$ \\
\hline \multirow[t]{2}{*}{ Interaction term $\left(T_{1} * T_{2}\right)$} & $7.643^{*}$ & $8.961^{* * *}$ & 0.904 & 2.085 \\
\hline & $(4.466)$ & $(3.680)$ & $(1.612)$ & $(1.392)$ \\
\hline Control variables & YES & YES & YES & YES \\
\hline Occupation fixed effects & $\mathrm{NO}$ & $\mathrm{NO}$ & $\mathrm{NO}$ & $\mathrm{NO}$ \\
\hline Industry fixed effects & NO & $\mathrm{NO}$ & $\mathrm{NO}$ & $\mathrm{NO}$ \\
\hline Observations & 224 & 224 & 935 & 935 \\
\hline Log pseudolikelihood & -183.59 & & -782.91 & \\
\hline Pseudo $R^{2}$ & 0.0993 & 0.225 & 0.124 & 0.255 \\
\hline \multicolumn{5}{|c|}{$\begin{array}{l}\text { Note: (1) and (3) are estimates from ordered Probit model, the dependent variable being equal to } 1 \text { when the respondent } \\
\text { intends to leave the labor market before } 60,2 \text { when his intended exit age ranges from } 60 \text { to } 64 \text {, and } 3 \text { if he intends to leave } \\
\text { the labor market at } 65 \text { or after. Standard errors (in parentheses) are clustered at the industry-occupation level, significance } \\
\text { levels being } 1 \%\left({ }^{* * *}\right), 5 \%\left(^{* *}\right) \text { and } 10 \%\left({ }^{*}\right) .(2) \text { and }(4) \text { are estimates from an OLS regression on the latent outcome associated } \\
\text { with retirement intention. The latent variable has been obtained using simulated residuals. The other control variables are } \\
\text { those used in the regressions reported in Table } 5 . \\
\text { Source: COI (2006)/INSEE-DARES-CEE, TWR survey (2006), French Labour Force Survey } 2006 .\end{array}$} \\
\hline
\end{tabular}

\section{Conclusion}

In this paper, we have investigated the role of productivity as a determinant of the workers' retirement behavior. While many studies have already analyzed the impact of senior workers' productivity on the firm's hiring and firing decision, our empirical analysis focuses on retirement intentions.

The main contribution of our paper is to show that in some jobs, characterized by a high training rate, technical change may induce workers to delay their retirement date. Using French data, we estimate that in jobs with a high probability of skill upgrading, the probability of a technical change computed at the industry-occupation level has a positive effect on the individual propensity to delay the retirement decision. However, in absence of training, technical change has a negative effect on the propensity to postpone the retirement decision. So, training may dampen the erosion effect of technical change on the retirement decision.

As it stands, this study has a few limitations. From a theoretical perspective, we do not endogenize in our framework the propensity of firms to train their older workers. From an empirical perspective, we decompose jobs by industry and occupation cells, but it would be useful to control for the characteristics of the firm in which each respondent is employed. Matched employer-employee data with information on retirement intentions would make possible to assess whether our findings may result from different employers' management practices regarding either the decision of adopting new technologies or the training policy within the firm.

\section{Endnotes}

${ }^{1}$ Other major contributions to the skill-biased technological progress literature are Berman et al. (1994), Machin and Van Reenen (1998), Krusell et al. (2000) or Caroli and Van Reenen (2001). 
${ }^{2}$ See Goos and Manning (2007), Autor et al. (2003), Autor et al. (2006), Spitz-Oener (2006) or Maurin and Thesmar (2004).

${ }^{3}$ Individuals perfectly anticipate the shift in the technological frontier between the first and the second period. For simplicity, we do not analyze the impact that the working decisions adopted by our cohort of interest concerning their old period have on the co-existing cohort of young workers via taxes. Similarly, we assume that productivity differentials between the young and the old cohort of workers will not influence the labor supply decision of the old cohort. Therefore, the consequences of potential interactions across cohorts are not analyzed here.

${ }^{4}$ Because we are exclusively analyzing the cohort entering the labor market in $t-1$, we simplify notation and represent the considered distribution of abilities by $\left[\underline{a}_{t-1}, \bar{a}_{t-1}\right]$, rather than $\left[\underline{a}_{t-2} b_{t-1}, \bar{a}_{t-2} b_{t-1}\right]$.

${ }^{5}$ Because education is assumed to be indexed to the state of technology, the ability distribution associated with the new cohort of young workers entering the labor market in $t$ will equal $a_{t}^{i}=\left[\underline{a}_{t}^{i}, \bar{a}_{t}^{i}\right]=\left[\underline{a}_{t-1}^{i} b_{t}, \bar{a}_{t-1}^{i} b_{t}\right]$. The new cohort of young workers has then the same ability distribution as the previous cohort, but shifted by $b_{t}$. This implies that the relative productivity of senior workers in simple jobs is deteriorated, while that of senior workers in complex jobs does not differ from the productivity of the new cohort.

${ }^{6}$ This parameter includes all non monetary factors affecting the financial trade-off of the retirement decision. It covers socio-economic factors, working conditions or health status.

${ }^{7}$ Intuitively, we easily deduce that a higher tax rate $\tau_{t}$ will lead the new cohort of workers entering the labor market at date $t$ to save less during the first period and work for a longer time during the second period. Similarly, productivity differentials between young workers entering the labor market and old workers, could discourage seniors to work. This type of interactions is behind the scope of this paper.

${ }^{8}$ If we had considered the demand side, we would probably observe an increase in the firing rate of these senior workers since their relative productivity with respect to the new cohort of workers entering the labor market is reduced. Because our model focuses on a single cohort, this type of interactions between cohorts is not considered. Moreover, in our case, we are considering a supply-side model.

${ }^{9}$ Overall, the TWR survey includes 12,451 individuals and contains three different parts. Part A includes all individuals aged 50-69 years old who are still working at the time of the survey. Part B is made up of individuals who are out of the labour force at the time of the survey, but who have already worked. Finally, part $\mathrm{C}$ concerns individuals who have never worked. Here we restrict our sample to workers interviewed in part A.

${ }^{10}$ There is also a "Don't know" category, which concerns only 54 respondents. These observations were discarded in our empirical analysis.

${ }^{11}$ More precisely individuals were asked: "Has your work changed over the last three years because of a change in the techniques used?".

${ }^{12}$ Using data from the Continuing Vocational Training Survey conducted on a representative sample of French firms, Lambert et al. (2009) show that the average duration of a training spell is 28 hours.

${ }^{13}$ These additional results are available upon request.

${ }^{14}$ The MCA generates quantitative scores or "dimensions" that maximize the average correlation among the qualitative variables. The indicator of ICT-intensity used for each firm in 2006 is computed by regressing the first dimension, reflecting the intensity of use of ICT tools, on the 15 items reported in Table 3 . The estimated coefficients represent the weight of each item and can be interpreted as a metric, determined by the set of situations specific to 2006. The synthetic indicator is obtained from a weighted sum of these items. Note that this metric estimated in 2006 has been used to compute the synthetic indicator of intensity of ICT use in 2003 for temporal comparison, as recommended by Greenan 
and Mairesse (2006). For more details about the methodology, see Greenan and Mairesse (2006) and Bigi et al. (2013).

${ }^{15}$ The high intensity of technological change is measured by the last quartile of the continuous indicator.

${ }^{16}$ We have also estimated the same regressions introducing wage as a control variable and reach similar conclusions. These additional estimates are available upon request.

${ }^{17}$ We have also estimated an ordered regression with seniority as additional covariate. This does not affect the positive coefficient associated with the distance to the full pension age.

${ }^{18}$ For a recent application of simulated residuals to recover a latent variable, see Wolff (2012).

${ }^{19}$ To check the validity of our results, we have also extended Ai et al. (2004) method to the case of an ordered probit specification. We compute the average marginal effect of the interaction term on each probability of selecting a specific age group for exit age and determine the corresponding standard errors using the delta method. Details on calculation and results are available upon request.

${ }^{20}$ Using French data Lambert et al. (2009) show that high ability workers (especially managers) have the highest access rate to training.

\section{Appendix}

\section{Detailed equations of the theoretical model}

If the individual does not work during his second period of time, i.e. $z_{t}^{C}=z_{t}^{S}=0$, we have:

$$
\begin{aligned}
& s_{t-1}^{i S}=\frac{\beta}{1+\beta}\left(1-\tau_{t-1}\right) w_{t-1}^{i}-\frac{\rho_{t} w_{t}^{i}}{R(1+\beta)}=\frac{\beta}{1+\beta}\left(1-\tau_{t-1}\right) a_{t-1}^{i}-\frac{\rho_{t} a_{t-1}^{i}}{R(1+\beta)} \\
& s_{t-1}^{i C}=\frac{\beta}{1+\beta}\left(1-\tau_{t-1}\right) w_{t-1}^{i}-\frac{\rho_{t} w_{t}^{i}}{R(1+\beta)}=\frac{\beta}{1+\beta}\left(1-\tau_{t-1}\right) a_{t-1}^{i}-\frac{\rho_{t} a_{t-1}^{i} b_{t}}{R(1+\beta)}
\end{aligned}
$$

Future consumption is given in this case by:

$$
\begin{aligned}
& d_{t}^{i S}=\frac{\beta}{1+\beta}\left(R\left(1-\tau_{t}\right) w_{t-1}^{i}+\rho_{t} w_{t}^{i}\right)=\frac{\beta}{1+\beta}\left(R\left(1-\tau_{t}\right) a_{t-1}^{i}+\rho_{t} a_{t-1}^{i}\right) \\
& d_{t}^{i C}=\frac{\beta}{1+\beta}\left(R\left(1-\tau_{t}\right) w_{t-1}^{i}+\rho_{t} w_{t}^{i}\right)=\frac{\beta}{1+\beta}\left(R\left(1-\tau_{t}\right) a_{t-1}^{i}+\rho_{t} a_{t-1}^{i} b_{t}\right)
\end{aligned}
$$

If the individual decides to work during the second period of life, i.e. $z_{t}^{k}>0$ for $k=C, S$, his optimal choices depend on the type of job we consider:

$$
\begin{aligned}
z_{t}^{i C} & =\frac{\left(1-\tau_{t}\right)(1+\beta)-\rho(1+\beta(1+\gamma))-\gamma R \beta\left(1-\tau_{t-1}\right) 1 / b_{t}}{\left(1-\tau_{t}-\rho\right)(1+\beta+\gamma \beta)} \\
z_{t}^{i S} & =\frac{\left(1-\tau_{t}\right)(1+\beta)-\rho(1+\beta(1+\gamma))-\gamma R \beta\left(1-\tau_{t-1}\right)}{\left(1-\tau_{t}-\rho\right)(1+\beta+\gamma \beta)}
\end{aligned}
$$

Savings are obtained by replacing in equation (9):

$$
\begin{aligned}
& s_{t-1}^{i C}=\frac{1}{R(1+\beta+\gamma \beta)}\left[\beta R\left(1-\tau_{t-1}\right)(1+\gamma) a_{t-1}^{i}-a_{t-1}^{i} b_{t}\left(1-\tau_{t}\right)\right] \\
& s_{t-1}^{i S}=\frac{1}{R(1+\beta+\gamma \beta)}\left[\beta R\left(1-\tau_{t-1}\right)(1+\gamma) a_{t-1}^{i}-a_{t-1}^{i}\left(1-\tau_{t}\right)\right]
\end{aligned}
$$


Future consumption is then given by:

$$
\begin{aligned}
d_{t}^{i C}= & R\left[\frac{1}{R(1+\beta+\gamma \beta)}\left[\beta R\left(1-\tau_{t-1}\right)(1+\gamma) a_{t-1}^{i}-a_{t-1}^{i} b_{t}\left(1-\tau_{t}\right)\right]\right] \\
& +\left(1-\tau_{t}\right) a_{t-1}^{i} b_{t}\left[\frac{1-\tau_{t}-\rho+\beta\left(1-\tau_{t}-\rho(1+\gamma)\right)-\gamma R \beta\left(1-\tau_{t-1}\right) 1 / b_{t}}{\left(1-\tau_{t}-\rho\right)(1+\beta+\gamma \beta)}\right] \\
& +\rho a_{t-1}^{i} b_{t}\left(1-\frac{1-\tau_{t}-\rho+\beta\left(1-\tau_{t}-\rho(1+\gamma)\right)-\gamma R \beta\left(1-\tau_{t-1}\right) 1 / b_{t}}{\left(1-\tau_{t}-\rho\right)(1+\beta+\gamma \beta)}\right) \\
d_{t}^{i S}= & R\left[\frac{1}{R(1+\beta+\gamma \beta)}\left[\beta R\left(1-\tau_{t-1}\right)(1+\gamma) a_{t-1}^{i}-a_{t-1}^{i}\left(1-\tau_{t}\right)\right]\right] \\
& +\left(1-\tau_{t}\right) a_{t-1}^{i}\left[\frac{1-\tau_{t}-\rho+\beta\left(1-\tau_{t}-\rho(1+\gamma)\right)-\gamma R \beta\left(1-\tau_{t-1}\right)}{\left(1-\tau_{t}-\rho\right)(1+\beta+\gamma \beta)}\right] \\
& +\rho a_{t-1}^{i}\left(1-\frac{1-\tau_{t}-\rho+\beta\left(1-\tau_{t}-\rho(1+\gamma)\right)-\gamma R \beta\left(1-\tau_{t-1}\right)}{\left(1-\tau_{t}-\rho\right)(1+\beta+\gamma \beta)}\right)
\end{aligned}
$$

The budget constraint at date $t$ equals:

$$
\rho\left[1-z_{t}^{S}\left(\tau_{t}, \tau_{t-1}\right)\right] W_{t}^{o S}+\rho\left[1-z_{t}^{C}\left(\tau_{t}, \tau_{t-1}\right)\right] W_{t}^{o C}=\tau_{t}\left[W_{t}^{Y}+W_{t}^{O}\right]
$$

where,

$$
\begin{aligned}
W_{t}^{o S} & =\int_{0}^{a_{t-1}^{i *}} w_{t}^{i o S} d i=\int_{0}^{a_{t-1}^{i *}} a_{t-1}^{i} d a=\frac{\left(a_{t-1}^{i *}\right)^{2}}{2} \\
W_{t}^{o C} & =\int_{a_{t-1}^{i *}}^{1} w_{t}^{i o C} d i=\int_{a_{t-1}^{i *}}^{1} a_{t-1}^{i} b_{t} d a=\frac{b_{t}}{2}\left(1-\left(a_{t-1}^{i *}\right)^{2}\right) \\
W_{t}^{Y} & =\int_{0}^{1} w_{t}^{i Y} d i=\int_{0}^{1} a_{t-1}^{i} b_{t} d i=\frac{\left[\left(a_{t-1}^{i}\right)^{2}\right]_{0}^{1}}{2} b_{t}=\frac{b_{t}}{2} \\
W_{t}^{O} & =z_{t}^{S}\left(\tau_{t}, \tau_{t-1}\right) \int_{0}^{a_{t-1}^{i *}} w_{t}^{i o S} d i+z_{t}^{C}\left(\tau_{t}, \tau_{t-1}\right) \int_{a_{t-1}^{i *}}^{1} w_{t}^{i o C} d i \\
& =z_{t}^{S}\left(\tau_{t}, \tau_{t-1}\right) \frac{\left(a_{t-1}^{i *}\right)^{2}}{2}+z_{t}^{C}\left(\tau_{t}, \tau_{t-1}\right) \frac{b_{t}}{2}\left(1-\left(a_{t-1}^{i *}\right)^{2}\right)
\end{aligned}
$$

Setting to zero equation (13) leads to:

$$
\bar{\gamma}^{k} R=\frac{(1+\beta)\left(1-\tau_{t}-\rho\right)}{\beta R\left(1-\tau_{t-1}\right) \frac{w_{t-1}}{w_{t}}-\beta \rho}
$$

for $k=C, S$.

\section{Competing interests}

The IZA Journal of Labor Economics is committed to the IZA Guiding Principles of Research Integrity. The authors declare that they have observed these principles.

\section{Acknowledgement}

We would like to thank two anonymous reviewers and conference participants at T2M (2012), EALE (2013) and ESPE (2013) for their comments and suggestions on a previous draft. We are also grateful to Nathalie Greenan for her help with the COI data. Any remaining errors are ours.

Responsible editor: V. Joseph Hotz

\section{Author details}

${ }^{1}$ University of Maine (GAINS-TEPP, Pres UNAM), CEE, France. ${ }^{2}$ University of Angers (GRANEM) and CREST and GAINS-TEPP IRES, France. ${ }^{3}$ IRES, Belgium. ${ }^{4}$ University of Nantes (LEMNA) and INED, France. 
Received: 2 July 2014 Accepted: 15 July 2014

\section{Published: 29 Sep 2014}

\section{References}

Acemoglu D, Pischke J-S (1998) Why do firms train? Theory and evidence. Quarterly J Econ 113:79-119

Ahituv A, Zeira J (2011) Technical progress and early retirement. Econ J 121:171-193

Ai C, Norton E, Wang H (2004) Computing interaction effects and standard errors in logit and Probit models. Stat J 4(2):154-167

Aubert P, Caroli E, Roger M (2006) New technologies, workplace organization and the age structure of the workforce: firm-level evidence. Econ J 116:73-93

Autor D, Levy F, Kearney M (2006) The polarization of the US labor market. Am Econ Rev 96(2):189-194

Autor D, Levy F, Murnane R (2003) The skill content of recent technological change: an empirical exploration. Q J Econ 118(4):1279-1333

Bartel A, Sichermann N (1993) Technological change and retirement decisions of older workers. J Lab Econ 11(1):162-182

Beckmann M (2007) Age-biased technological and organizational change: Firm-level evidence and management implications. WP Faculty of Business and Economics, University of Basel, vol. 05-07

Behaghel L, Caroli E, Roger M (2010) Départ des travailleurs âgés, formation continue dans les entreprises innovantes. Travail et Emploi 121:21-32

Belan P, Messe PJ, Wolff FC (2010) Postponing retirement age and labor force participation: the role of family transfers. Louvain Econ Rev 76(4):347-369

Benitez-Silva H, Dwyer D (2005) The rationality of retirement expectations and the role of new information. Rev Econ Stat 87(3):587-592

Berman E, Bound J, Griliches Z (1994) Changes in the demand for skilled labor within U.S. manufacturing: evidence from the Annual Survey of Manufacturers. Q J Econ 109:367-397

Bigi M, Greenan N, Hamon-Cholet S, Lanfranchi J (2013) Y-a-t-il convergence de l'engagement des salariés du secteur privé et des agents de la fonction publique d'État face aux changements organisationnels? Revue d'Econ Politique 123(3):377-401

Borghans L, Weel B (2002) Do older workers have more trouble using a computer than younger workers. Res Lab Econ 21:139-173

Bresnahan TF, Brynjolfsson E, Hitt LM (2002) Information technology, workplace organization, and the demand for skilled labor: firm-level evidence. Q J Econ 117(1):339-376

Caroli E, Van Reenen J (2001) Skilled biased technological change? evidence from a pannel of British and French establishments. Q J Econ 116(4):1449-1492

Carre M, Drouot D (2004) Pace versus type: the effect of economic growth on unemployment and wage patterns. Rev Econ Dyn 7:737-757

Chari W, Hopenhayn H (1991) Vintage human capital, growth and the diffusion of new technology. J Pol Econ 99(6):1142-1165

Cheron A, Hairault J-O, Langot F (2013) Life-cycle equilibrium unemployment. Journal of Labor Economics 31(4):843-882

Cheron A, Langot F, Moreno-Galbis E (2011) Labor market institutions and technological employment. Economica 78(309):159-186

Dwyer DS, Hu J (2000) Retirement expectations and realizations: the role of health shocks and economic factors. In: Hammond PB, Mitchell OS, Rappaport AM (eds) Forecasting retirement needs and retirement wealth. University of Pennsylvania Press, Philadelphia

Friedberg $L$ (2003) The impact of technological change on older workers: evidence from data on computer use. Ind Lab Relations Rev 56(3):511-529

Goos M, Manning A (2007) Lousy and lovely jobs: the rising polarization of work in britain. Rev Econ Stat 89(1):118-133

Gouriéroux C, Monfort A, Renault E, Trognon A (1987) Simulated residuals. J Econometrics 34:201-252

Greenan N, Mairesse J (2006) Les changements organisationnels, l'informatisation des entreprises et le travail des salaries. Revue Economique 57(6):1137-1175

Hairault JO, Langot F, Sopraseuth T (2010) Distance to retirement and older workers employment: the case for delaying the retirement age. J Eur Econ Assoc 8(5):1034-1076

Jovanovic B, Nyarko Y (1996) Learning by doing and the choice of technology. Econometrica 64(6):1299-1310

Krusell P, Ohanian LE, Rios-Rull JV, Violante GL (2000) Capital skill complementarity and inequality: a macroeconomic analysis. Econometrica 68(5):1029-53

Lambert M, Marion-Vernoux I, Sigot JC (2009) Quand la formation continue? Reperes sur les pratiques de formation des employeurs et des salaries. Cereq, Marseille

Langot F, Moreno-Galbis E (2013) Does the growth process discriminate against older workers? J Macroeconomics 38:286-306

Ljunqvist J, Sargent T (2008) Two questions about European unemployment. Econometrica 76:1-29

Machin S, Van Reenen J (1998) Technology and changes in skill structure: Evidence from seven OECD countries. Q J Econ 113:1215-44

Maurin E, Thesmar D (2004) Changes in the functional structure and demand for skills. J Lab Econ 22(3):639-664

Michel P, Pestieau P (2000) Retraite par répartition et âge de la retraite. Revue Economique 51:15-30

Moreno-Galbis E (2012) The impact of TFP growth on the unemployment rate: does on-the-job training matter? European Econ Rev 56:1692-1713

Mortensen D, Pissarides C (1998) Technological progress, job creation and job destruction. Rev Econ Dyn 1:733-753

Moulton B (1990) An illustration of a pitfall in estimating the effects of aggregate variables on micro unit. Rev Econ Stat 72(2):334-338

Parente S (1994) Technology adoption, learning by doing and economic growth. J Econ Theory 63(2):346-369

Picchio M, Van-Ours JC (2013) Retaining through training even for older workers. Econ Educ Rev 32:29-48 
Ronningen D (2007) Are technological change and organizational change biased against older workers? Firm-level evidence. Statistics Norway, Research Department Discussion Paper, vol. 512

Saint-Paul G (2009) Does the Welfare State Make Older Workers Unemployable. IDEI Working Paper. no. 569

Spitz-Oener A (2006) Technical change, job tasks and rising educational demands: looking outside the wage structure. J Lab Econ 24(2):235-270

Taylor MA, Shore L (1995) Predictors of planned retirement age: an application of Beehr's model. Psychol Aging 10(1):76-83

Wolff FC (2012) Decomposition of non-linear models using simulated residuals. Econ Lett 116:346-348

10.1186/2193-8997-3-8

Cite this article as: Messe et al:: Retirement intentions in the presence of technological change: theory and evidence from France. IZA Journal of Labor Economics 2014, 3:8

Submit your manuscript to a SpringerOpen ${ }^{\circ}$ journal and benefit from:

- Convenient online submission

- Rigorous peer review

- Immediate publication on acceptance

- Open access: articles freely available online

- High visibility within the field

- Retaining the copyright to your article

Submit your next manuscript at $\gg$ springeropen.com 